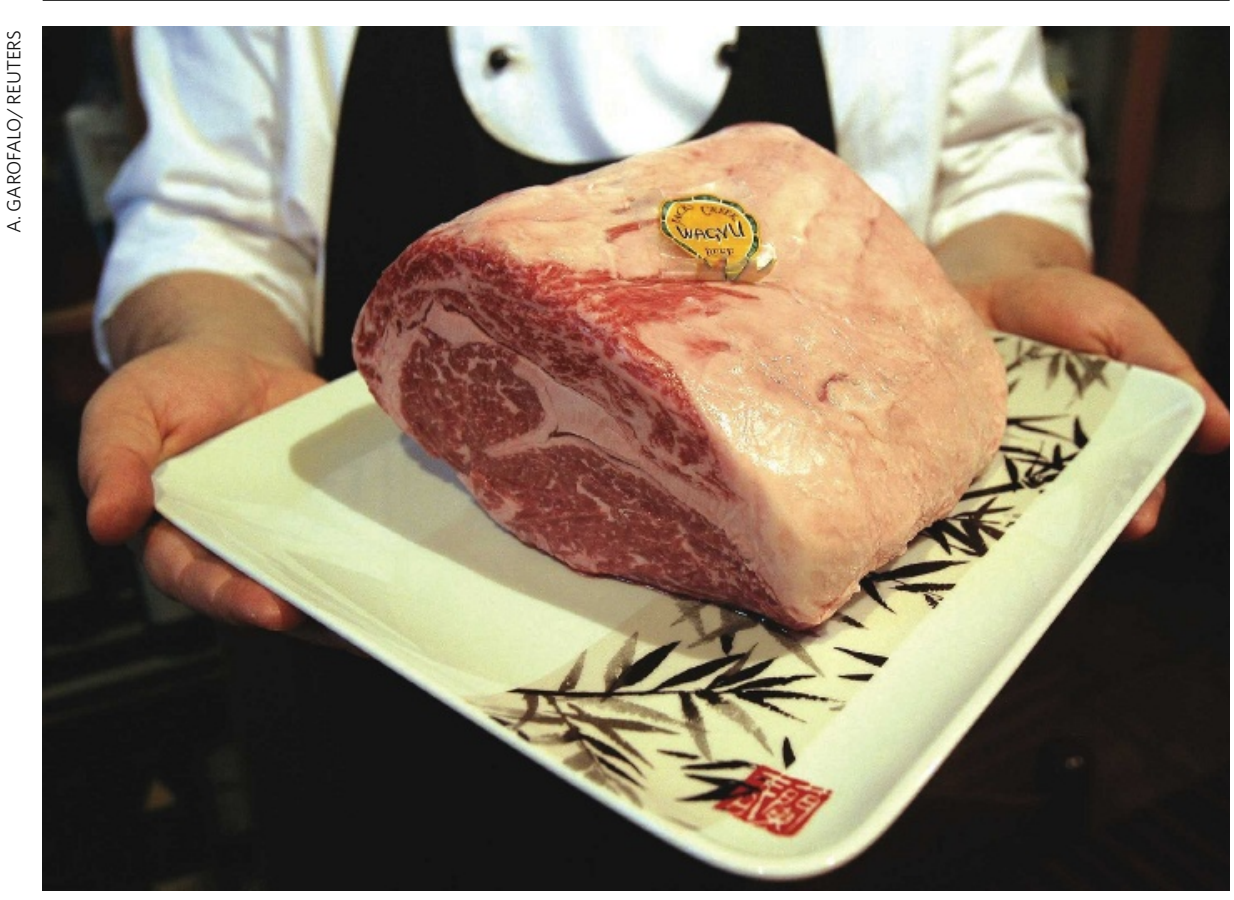

Seeking succulence: the goal of maximizing the taste of beef is furthered by a hand-held device.

\section{Meat meter measures marbled muscles}

Japanese researchers have developed a device to objectively assess the deliciousness of meat - an important concern for a nation that is especially demanding about the quality of its beef.

Japan's Wagyu beef is prized for its marbled fat, which gives the meat its particular flavour, succulence and tenderness. But marbling is not the whole story, says Masakazu Irie, an expert in animal husbandry at the University of Miyazaki. Meat doesn't necessarily get tastier as marbling increases. "If the fat is hard, with a high melting point, it can be like eating a candle," he says. But not all soft fat is good either - fat high in linoleic acid is soft and still unpleasant, Irie notes.

Irie and his colleagues have come up with a hand-held, portable device that measures the concentration of oleic acid in the meat. This monounsaturated fat, they say, is a reliable indicator of tastiness. A fibre-optic probe directs near-infrared light into the meat, and the light bounces off the fat with a signature dependent on the type of fat and its concentration. The result can be read within seconds and doesn't damage the meat.

But Carol Christensen, a former taste researcher at the Monell Chemical Senses Center in Philadelphia, Pennsylvania, says that Irie's device is unlikely to be able to replace the tongue. "Food manufacturers want to replace human sensory panels with metrics, but I think it is just a pipedream," she says. "There's a lot going on in your mouth."

Irie plans to use the device in another project led by Tadashi Kawamura at the National Livestock Breeding Center in Fukushima. Kawamura is trying to establish a system for rating beef based on its chemical properties. He has a panel of more than 10 trained beef tasters who are judging sensory characteristics, such as how tender, fatty and juicy the meat is. These data will then be matched with chemical data on the concentration of some 20 components in beef, including oleic acid and inosinic acid, which enhances umami, the taste associated with monosodium glutamate.

Kawamura hopes that supermarkets and restaurants might some day offer steaks with a standardized ranking, perhaps on a scale of $1-5$, for qualities such as juiciness and fattiness. David Cyranoski

\section{English grants under review}

Proposals to radically alter the way English universities are funded could mean that young researchers lose out, academic groups warned last week.

In 2009, a system of 'metrics' will be rolled out to replace the Research Assessment Exercise (RAE) peer-review system in England - the first country to apply metrics to funding on this scale. The new Research Excellence Framework will allocate its $£ 1$ billion (US $\$ 2$ billion) a year funding to departments mainly on the basis of citations, rather than RAE grade. It is an attempt by the Higher Education Funding Council for England (HEFCE) to make the process fairer and the applications process easier.

But academic groups are worried that the new system might discriminate against researchers who have not yet had time to build up many citations. “Obviously you don't want a system that penalizes people at the start of their careers or people who take career breaks," says Steve Smith, chair of the 1994 Group, an advocacy group that represents a number of high-profile UK universities. "It does worry me."

A consultation on the new metrics, which closed this month, reveals that academic groups are not entirely against it, but they do have some concerns. Policy experts are uneasy about a wholesale move away from peer review and concerned that the metrics system will not correctly assess the merits of some disciplines, be very costly for institutions initially and may discourage interdisciplinary research. Last year, the HEFCE was warned by its own audit committee that "a number of technical areas require further work if the new system is to have credibility".

"The RAE undoubtedly had flaws, and it was revised continually to address them," says Bahram Bekhradnia, director of the UK Higher Education Policy Institute. "But it was probably better than anything that is likely to appear."

However the HEFCE, which is now analysing the responses to the consultation, defends the new system and thinks that the university sector is now broadly behind the proposals. Daniel Cressey 